\title{
Diseño de un instrumento de gestión para evaluar la Cultura de Seguridad en el trabajo
}

José Luis RoJas CASTRO ${ }^{1}$ FÉLIX TiNOCO ÁNGELES ${ }^{2}$

ReCiBIDO: 19/01/2019 AcEPTADo: 25/04/2019

\section{RESUMEN}

La Cultura de Seguridad que prevalece dentro de una organización, la forma en que esta aborda y gestiona los problemas de seguridad, es una influencia importante en el comportamiento que tiene relación con la seguridad de las personas en el trabajo. Por ese motivo, es esencial que cada organización pueda identificar los factores que inciden en ella, y que además los evalúen objetivamente.

El presente trabajo de investigación propone identificar los factores que inciden en la Cultura de Seguridad y la posibilidad de establecer una escala de calificación cualitativa para cada uno de ellos. Así, del conocimiento adecuado de cada uno de estos factores se sugieren acciones en seguridad más objetivas, certeras y efectivas. La revisión de trabajos europeos previos, orientada a lo objetivo, dio lugar al desarrollo de una metodología propia para diseñar una herramienta aplicable al medio local que carece de ella. El producto obtenido fue un cuestionario dirigido a la fuerza laboral, que evaluó 32 de 43 indicadores identificados con posible incidencia en la Cultura de Seguridad, incluyendo la descripción de cinco niveles de desarrollo para cada indicador. Finalmente, se validó el diseño de la herramienta local para evaluar la Cultura de Seguridad y quedó confirmada la incidencia de cuatro factores dentro de ella: liderazgo en seguridad, comunicación efectiva, participación del personal en la construcción de la seguridad y existencia de una cultura de aprendizaje continuo, asociados a 24 indicadores.

Palabras-claves: Cuestionario; Cultura de Seguridad; liderazgo en seguridad; comunicación efectiva; participación del personal; cultura de aprendizaje.

\section{INTRODUCCIÓN}

Cuanto mejor una organización conozca los factores que afectan a la Cultura de Seguridad y el nivel de desarrollo de estos, podrá plantear acciones en seguridad más ajustadas a su realidad, más efectivas y empleando menos tiempo para alcanzar sus metas, encaminando su sistema de gestión de seguridad hacia la mejora continua. Ello es requerido mediante la Ley de Seguridad y Salud en el Trabajo (Ley N. ${ }^{\circ}$ 29783), en su artículo 18 (Congreso de la República, 2011), y el reglamento de la Ley DS-005-2012-TR, artículo 26 (Ministerio de Trabajo y Promoción de Empleo, 2012).

Los resultados obtenidos de las acciones emprendidas en seguridad no siempre van acordes con los esfuerzos dispuestos para ello, y solo en pocas organizaciones se alcanza un cambio muy positivo hacia la seguridad por parte de los trabajadores. En contraposición, en la mayoría de las organizaciones, solamente ocurren cambios pequeños y muy poco significativos en seguridad, pese a que en muchas de ellas se aplican inversiones y recursos importantes. Esto ocurre porque no existe conocimiento y evaluación formal de los factores que inciden en la Cultura de Seguridad, y a que las acciones propuestas en la gestión de seguridad son tomadas a partir de la revisión de indicadores de siniestralidad y de cumplimiento de programas de trabajo. Ellas omiten factores como la comunicación, la participación y el compromiso de los trabajadores con la seguridad. Las valoraciones son subjetivas y ello es comprobable al cierre de cada año de trabajo, pues muchos esfuerzos resultan desalineados del contexto de la organización, y los progresos esperados no son alcanzados e incluso se registran retrocesos.

\section{Estudios previos referidos al tema de investigación}

La revisión de la bibliografía respecto al asunto cubre los últimos treinta años y está orientada a los siguientes temas clave:

1 Ingeniero mecánico y bachiller en Ingeniería Industrial por la Universidad Nacional Mayor de San Marcos. Actualmente es docente en el Centro Preuniversitario de la Pontificia Universidad Católica del Perú y es asistente de docencia en la PUCP. E-mail: rojas.j@pucp.edu.pe

2 Magíster en Gestión Operaciones y Servicios Logísticos por la Universidad Nacional Mayor de San Marcos. Actualmente, es consultor independiente. E-mail: tinocofelix@gmail.com 
- Qué se mide: Cultura de Seguridad, clima de seguridad, cultura organizacional, percepciones, actitud y/o conducta de las personas, factores de comportamiento, relaciones interorganizacionales.

- Criterios y/o indicadores de evaluación de la Cultura de Seguridad: enfocado a discernir las características positivas y negativas.

- Herramientas de evaluación y medición de la Cultura de Seguridad.

La investigación inició con la revisión de compilaciones de los estudios desarrollados respecto a Cultura de Seguridad (Gadd, 2002; Human Engineering for the Health and Safety Executive, 2005b). Posteriormente, se revisaron documentos que contenían conceptos y definiciones relacionados con la Cultura de Seguridad, el clima de seguridad y la cultura organizacional (Cooper, 2000; Guldenmund, 2000 y 2010).

Asimismo, se integraron documentos con el objetivo de obtener el mejor entendimiento de los factores que determinan la seguridad en una organización, en razón a que fueron desarrollados luego de la ocurrencia de accidentes mayores, entre los cuales están el accidente del sistema ferroviario inglés en Ladbroke, que dio lugar a un reporte completo de investigación (The Rt Hon Lord Cullen PC, 2001), y el accidente en Chernóbyl, con motivo del cual se hizo una revisión del concepto de Cultura de Seguridad y los factores que inciden en ella (International Nuclear Safety Advisory Group, 1991).

También hubo la oportunidad de revisar el documento que redactó la International Atomic Energy Agency (1992), en el cual se listaron las condiciones y omisiones presentes cuando ocurrió el accidente en Chernóbyl, que fue base para la propuesta de un cuestionario elaborado por el Consejo Internacional de Seguridad Atómica (International Nuclear Safety Advisory Group, 2002), con preguntas dirigidas a los distintos niveles operativos y administrativos, orientado a evaluar las contribuciones personales en la mejora de la Cultura de Seguridad.

En adición, se tuvo como referencia el trabajo de Carvalho (2011), el cual identificó factores organizacionales vinculados con la ocurrencia de accidentes laborales, entre los que se hallan el comportamiento del empleado, la gestión participativa, el comportamiento del departamento de seguridad, la percepción de los riesgos, el liderazgo, la percepción de justicia y los procesos de comunicación.
Además de ello, se revisaron documentos que propusieron herramientas con el fin de evaluar la Cultura de Seguridad y que analizaron los factores que inciden en ella. Uno de estos documentos aplicado al sector ferroviario inglés fue el de Human Engineering for the Health and Safety Executive (2005a), el cual se apoyaba en los estudios y focus group previamente trabajados, concluyendo con una herramienta en la forma de cuestionario con preguntas abiertas y cerradas, y puntos de evidencia para cada factor. Un segundo documento estuvo dirigido a empresas del sector químico, propuesto por Grillo (2013), el cual a pesar de su complejidad por las explicaciones con enfoques psicológicos detalla una metodología de validación de los factores con herramientas estadísticas, ello para modificar su agrupación hasta lograr una muy buena correlación y fiabilidad que permite comparar los niveles de seguridad entre colectivos dentro de una organización. Un tercer documento, de Bjørneide (2003), está referido a la propuesta de una herramienta para evaluar la Cultura de Seguridad en el sistema ferroviario europeo en la forma de un cuestionario, cuyo principal objetivo era mejorar la Cultura de Seguridad promoviendo procesos y discusiones de grupo colaborativos, dentro y entre organizaciones.

Por último, como referencia a los indicadores en cada uno de los factores de seguridad, fue revisada una guía de Oil \& Gas Producers (2010) para la selección de herramientas para el avance de la Cultura de Seguridad desarrollada por los productores del petróleo y una guía de Morales-Vallejo (2011) para poder construir un cuestionario, la cual resulta trascendental para emitir una propuesta propia.

\section{Aplicabilidad de los instrumentos existentes}

Aunque hay varias herramientas desarrolladas para evaluar la Cultura de Seguridad en otros países, no es conveniente aplicarlos a la realidad local de manera directa, puesto que existe real influencia de antecedentes culturales, sociales y económicos, así como de la cultura desarrollada en cada organización del trabajo. Así, resulta conveniente diseñar un instrumento propio para evaluar la Cultura de Seguridad en el medio local, de modo que su empleo brinde resultados útiles para propulsar el proceso de la mejora continua.

\section{MATERIALES Y MÉTODOS}

\section{Método}

Es una investigación cuantitativa, de tipo prospectivo, transversal, descriptiva y explicativa. 


\section{Metodología para el diseño de la herramienta}

A partir de la revisión de la bibliografía referida a la caracterización de la Cultura de Seguridad y a las herramientas ya desarrolladas para evaluarla, se planteó un modelo que incluyó cinco variables: liderazgo en seguridad, comunicación efectiva bidireccional, participación del personal en la construcción de la seguridad, existencia de una cultura de aprendizaje continuo y actitud hacia la culpa. Cada variable fue analizada en dimensiones y subdimensiones, definiendo indicadores de desempeño para cada una de estas últimas. El análisis de cada indicador dio lugar a preguntas y cinco niveles de desarrollo establecidos para cada una, resultando en el diseño de un cuestionario.

Para determinar cada nivel de desarrollo, se diseñó un marco de referencia en gestión de seguridad, identificando los siguientes aspectos:

Planeamiento y organización: ¿qué sistemas hay en el lugar?

\section{Control: ¿quién es responsable?}

Efectividad: ¿cómo ocurre en la práctica?

Flujo de información: ¿qué pasa con la información colectada?

Monitoreo y revisión: ¿miden los resultados y acciones tomadas?

Una vez iniciado el desarrollo en cada uno de estos aspectos, se identificaron las características para cada indicador en cinco niveles de progreso, asemejando esta caracterización al nivel de madurez propuesto para la Cultura de Seguridad en Inglaterra (The Keil Centre for the Health and Safety Executive, 2000) el cual identifica cinco niveles de madurez: emergente, de gestión, participación, de cooperación y de mejora continua.

Los indicadores de desempeño inicialmente asociados a cinco variables dieron lugar a 43 preguntas que fueron reorganizadas en seis escenarios temáticos, con la intención de facilitar su análisis y respuesta por parte de los encuestados. Aquellos fueron: gestión de seguridad, observaciones de seguridad, gestión del cambio, transferencia de información sobre deberes del turno, situación degradada y gestión de incidentes. De las 43 preguntas, 32 eran aplicables a la fuerza laboral y 19 a directivos (de las cuales 8 son preguntas comunes a los trabajadores y 11 corresponden a conocimientos específicos de la gestión de seguridad).
Se completó el diseño de un cuestionario con 32 preguntas para trabajadores, que es el público objetivo. Asimismo, se le preparó un cuestionario de contraste con cinco preguntas de evaluación general para cada variable.

Las 19 preguntas aplicables a directivos brindan información complementaria, la cual apoya en la validación de lo reportado por la fuerza laboral objetivo.

\section{Población y muestra}

El cuestionario es una herramienta dirigida a las empresas contratistas del sector minero, las cuales tienen implementado un sistema de gestión de seguridad, de acuerdo a directrices internacionales como OHSAS 18001, aunque aún no certificado, y que además orientan sus esfuerzos para la mejora en la seguridad, en base a la gestión de factores de accidentabilidad (índices de siniestralidad) y a campañas de prevención en seguridad.

La muestra principal invitada a responder el cuestionario corresponde a la población total de trabajadores del área de servicios de mantenimiento de la empresa Robocon (cincuenta personas). Asimismo, con la intención de contar con información complementaria en seguridad, de parte de los directivos de la organización, se invitaron a diez de un total de doce personas. Del personal invitado, se desestimaron los formularios trabajados por personal con menos de un año en la empresa, considerando que podría carecer de conocimiento suficiente de la cultura organizacional y de seguridad en la empresa (ver tabla 1).

\section{Recolección de datos: cuestionario principal, complementario y de contraste}

Los diferentes cuestionarios aplicados a los trabajadores y a los directivos fueron previamente presentados a la alta gerencia para su conocimiento y aprobación. Por un lado, el cuestionario elaborado para directivos fue preparado por medio electrónico y puesto a disposición para su llenado con ayuda de la aplicación Socrative. Solo quedaron excluidos dos de los doce ejecutivos: el gerente y el subgerente de seguridad. Por otro lado, el cuestionario desarrollado para los trabajadores fue entregado en formato escrito, acompañado de un formulario de respuestas. Además, se preparó una presentación con diapositivas para cada pregunta y alternativas de respuesta, presentada y comentada por un facilitador. De esta manera, se incentivó la posibilidad de comprender adecuadamente cada pregunta y responder con la alternativa más adecuada. Al final, se tomó un cuestionario de contraste (general de 
evaluación de la Cultura de Seguridad) con cinco preguntas evaluando los factores propuestos como variables que determinan la Cultura de Seguridad también en medio escrito.

Tabla 1. Tamaño de la muestra tomada.

\begin{tabular}{|l|c|c|c|}
\hline Muestra & Empleados & Directivos & Total \\
\hline Población total & 50 & 12 & 62 \\
\hline Población invitada & 50 & 10 & 60 \\
\hline Muestra & 50 & 10 & 60 \\
\hline $\begin{array}{l}\text { Muestra productora de } \\
\text { datos }\end{array}$ & $\mathbf{3 1}$ & $\mathbf{7}$ & $\mathbf{3 8}$ \\
\hline $\begin{array}{l}\text { Muestra productora de } \\
\text { datos \% }\end{array}$ & $62 \%$ & $70 \%$ & $63,3 \%$ \\
\hline
\end{tabular}

Fuente: elaboración propia.

\section{RESULTADOS DEL ESTUDIO APLICADO EN UNA ORGANIZACIÓN ESPECÍFICA}

En el estudio principal participaron 31 empleados, incluyendo cuatro jefes de área $(12,9 \%)$, seis supervisores $(19,35 \%)$ y veintiún operadores y personal labor $(67,7 \%)$. En adición, siete directivos participaron en el estudio complementario.

\section{Valoración general según edad, formación y an- tigüedad}

Se apreció similar calificación de la Cultura de Seguridad por edad, formación y antigüedad (ver figura 1):
Recolección de datos: información general complementaria de empleados

El cuestionario dirigido a empleados brindó información general referente a formación y categoría de trabajo, la cual está incluida en la tabla 2.

Se obtuvo información de las respuestas según la edad de los trabajadores, formación, antigüedad en la organización y en el puesto de trabajo, la cual está detallada por pregunta en las figuras 2, 3, 4 y 5 , respectivamente. El objetivo fue reconocer diferencias según el colectivo escogido.

\section{Valoración por edad}

La calificación es similar, exceptuando a las personas que tienen desde 41 hasta 50 años (4 casos), quienes se diferencian por una menor puntuación que el resto (27 casos).

\section{Valoración por formación}

La figura 3 identifica que solo hay un caso de excepción para mantener una calificación similar en general. Ella corresponde a una persona con posgrado, quien califica bajo en quince preguntas (dos puntos menos que el resto promedio).

\section{Valoración por antigüedad en la organización}

La figura 4 presenta calificación similar en general, salvo por una persona con once a veinte años en

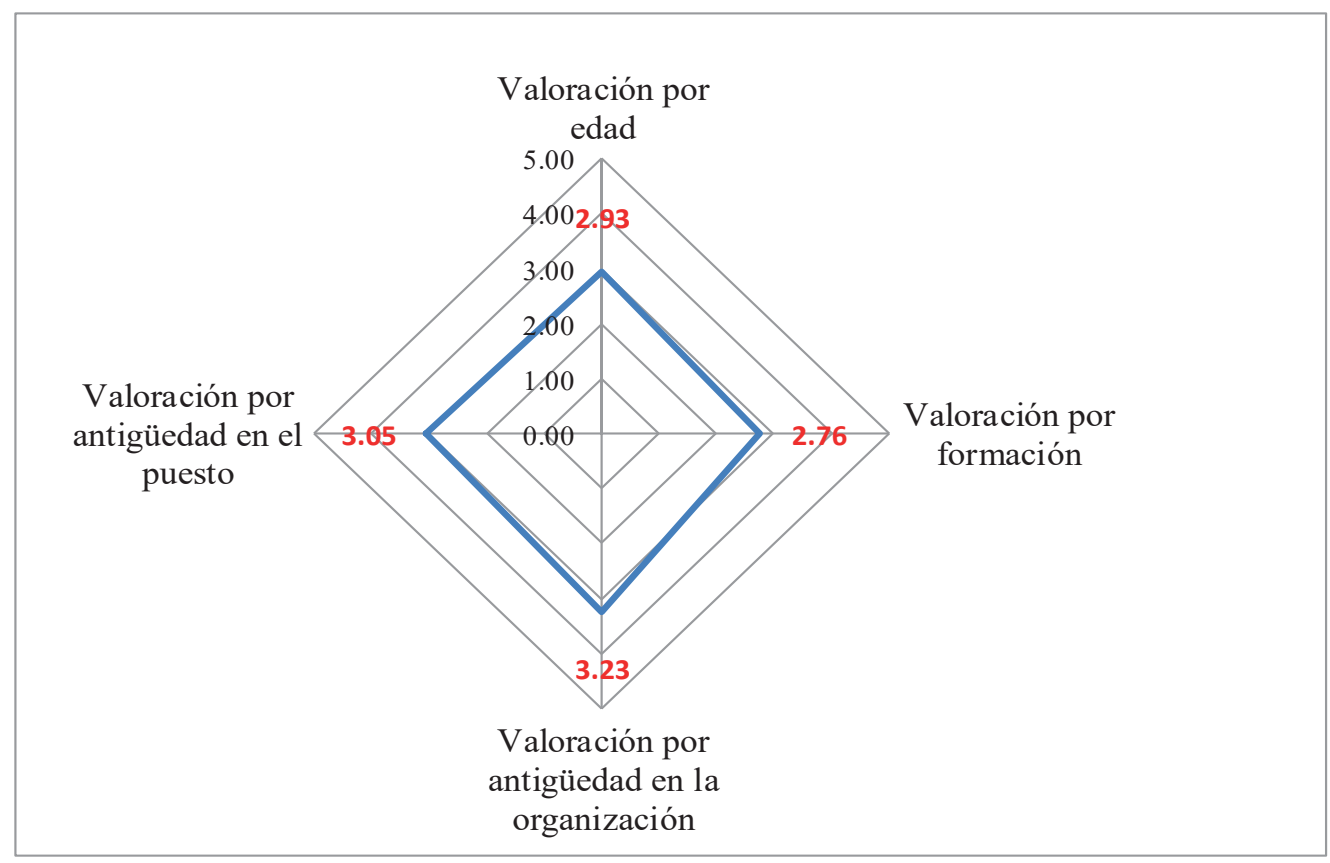

Figura 1. Valoración general por edad, formación y antigüedad.

Fuente: elaboración propia. 
Tabla 2. Formación y categoría de trabajo.

\begin{tabular}{|l|c|c|c|c|}
\hline \multicolumn{1}{|c|}{ Muestra } & Jefe de área & Supervisor & Personal labor & Porcentaje \\
\hline Posgrado & & 1 & & $3,2 \%$ \\
\hline Profesional graduado & 2 & 1 & 4 & $22,6 \%$ \\
\hline Formación técnica o universitaria incompleta & 2 & 3 & 11 & $51,6 \%$ \\
\hline Secundaria completa o Técnica incompleta & & 1 & 4 & $16,1 \%$ \\
\hline Primaria completa o Secundaria incompleta & & & 2 & $6,5 \%$ \\
\hline Total & 4 & 6 & 21 & $\mathbf{1 0 0} \%$ \\
\hline
\end{tabular}

Fuente: elaboración propia.

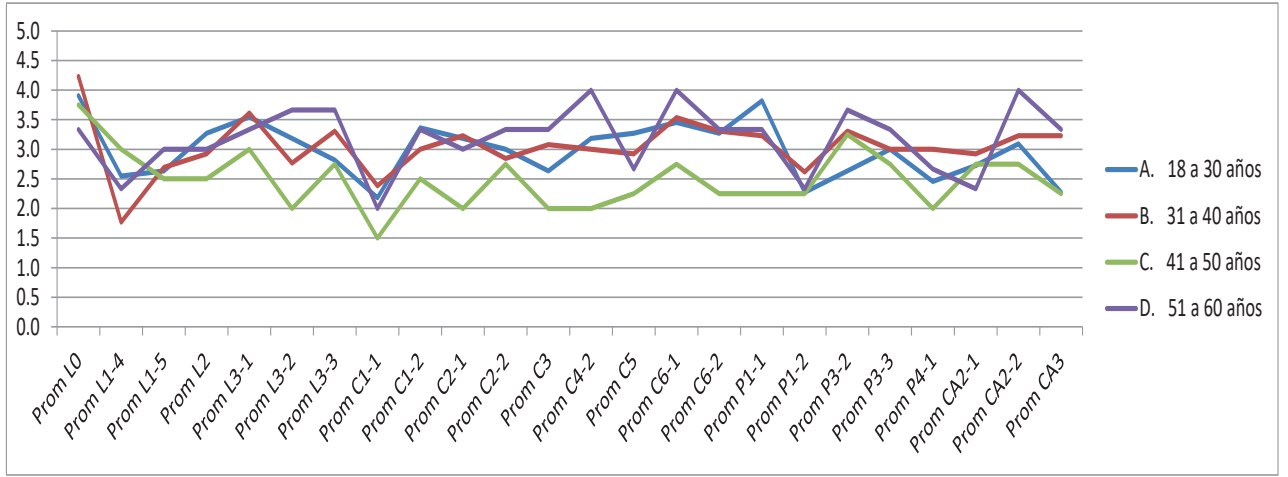

Figura 2. Valoración por edad.

Fuente: elaboración propia.

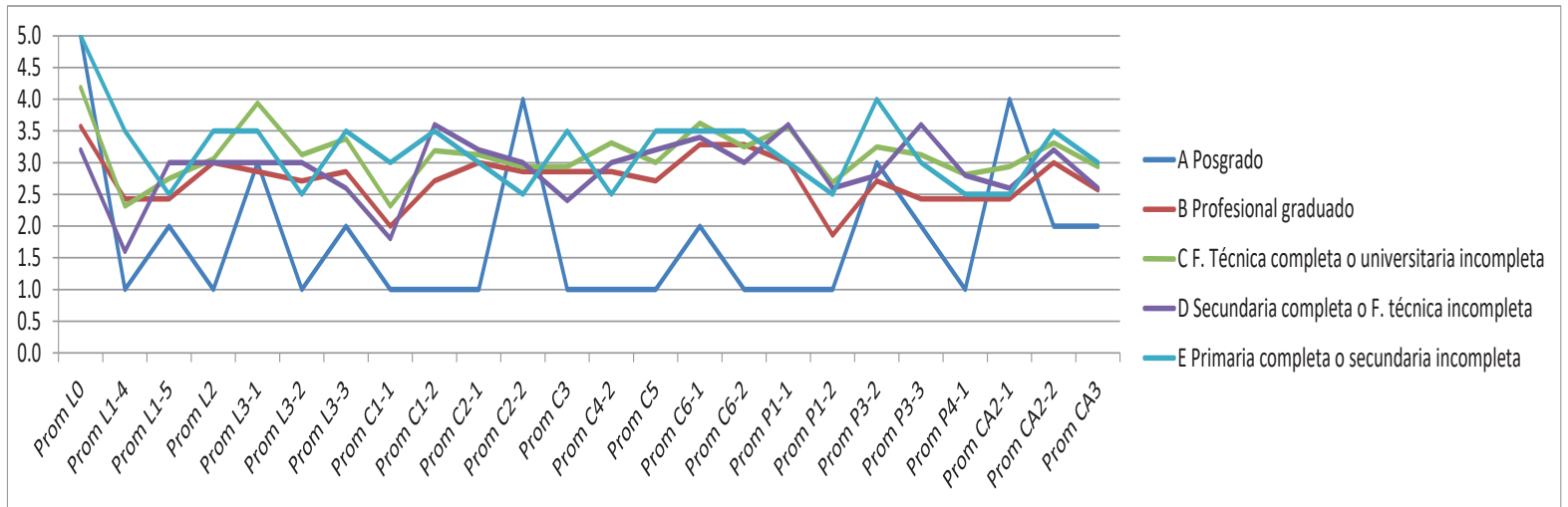

Figura 3. Valoración por formación.

Fuente: elaboración propia.

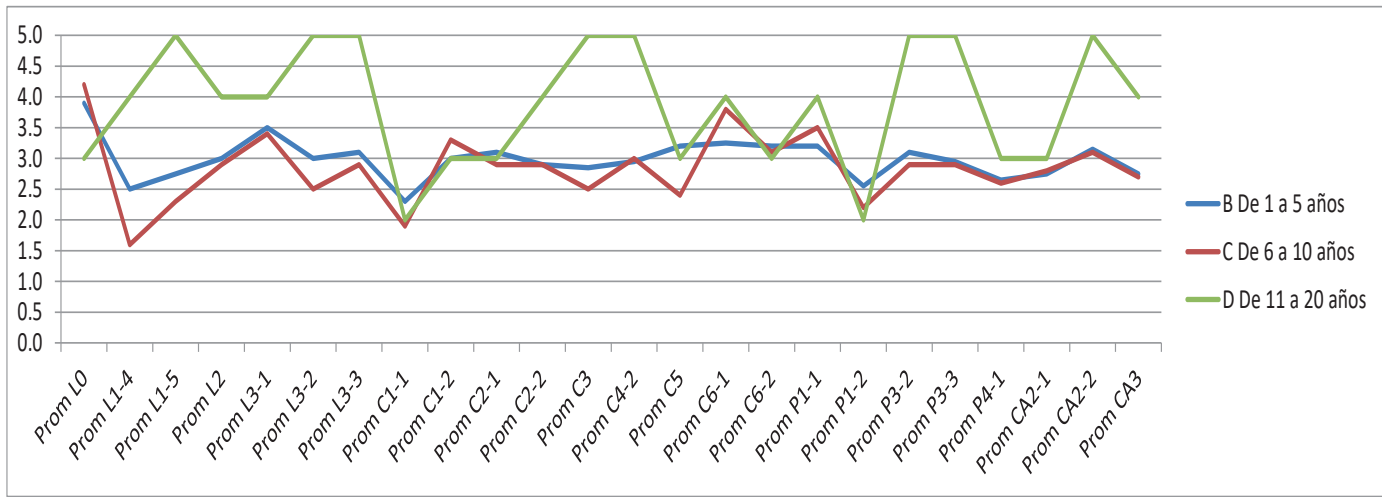

Figura 4. Valoración por antigüedad en la organización.

Fuente: elaboración propia. 
la empresa (la más antigua), quien calificó en trece ítems mejor que el promedio del resto.

\section{Valoración por antigüedad en el puesto}

La figura 5 confirma que la valoración para cada pregunta es muy similar y no depende de la antigüedad en el puesto.

\section{ANÁLISIS DE LOS DATOS COLECTADOS}

La validación de la información colectada respecto a los indicadores de la Cultura de Seguridad se inició con la evaluación de la fiabilidad en los cuestionarios para trabajadores y ejecutivos, descartando a aquellas que presentaron baja fiabilidad en el análisis por subescalas (a nivel variable).

Luego se efectuó la validación concurrente al integrar la información resultante de la revisión de documentación específica en seguridad, visita al entorno de trabajo y desarrollo de entrevistas directas con trabajadores y directivos, así como al análisis de los resultados contenidos en los cuestionarios para directivos y con el cuestionario de contraste.
Finalmente, se llevó a cabo la validación del constructo a través del estudio de correlaciones y regresión.

\section{Análisis de fiabilidad y validez del constructo}

Del análisis de los 32 indicadores en el cuestionario a trabajadores fue posible confirmar la fiabilidad en 24 , correspondientes a las cuatro primeras variables: liderazgo en seguridad, comunicación efectiva bidireccional, participación del personal en la construcción de la seguridad y existencia de una cultura de aprendizaje continuo. El coeficiente alfa de Cronbach para la variable: actitud hacia la culpa, no llegó a superar el valor mínimo establecido, denotando poca consistencia interna en el conjunto de ítems que las componen. Por tanto, se efectuó prueba de correlación solo a las cuatro primeras variables.

La tabla 3 incluye las preguntas que se mantuvieron y aquellas que se eliminaron del cuestionario para obtener el más alto coeficiente alfa de Cronbach $(0,944)$.

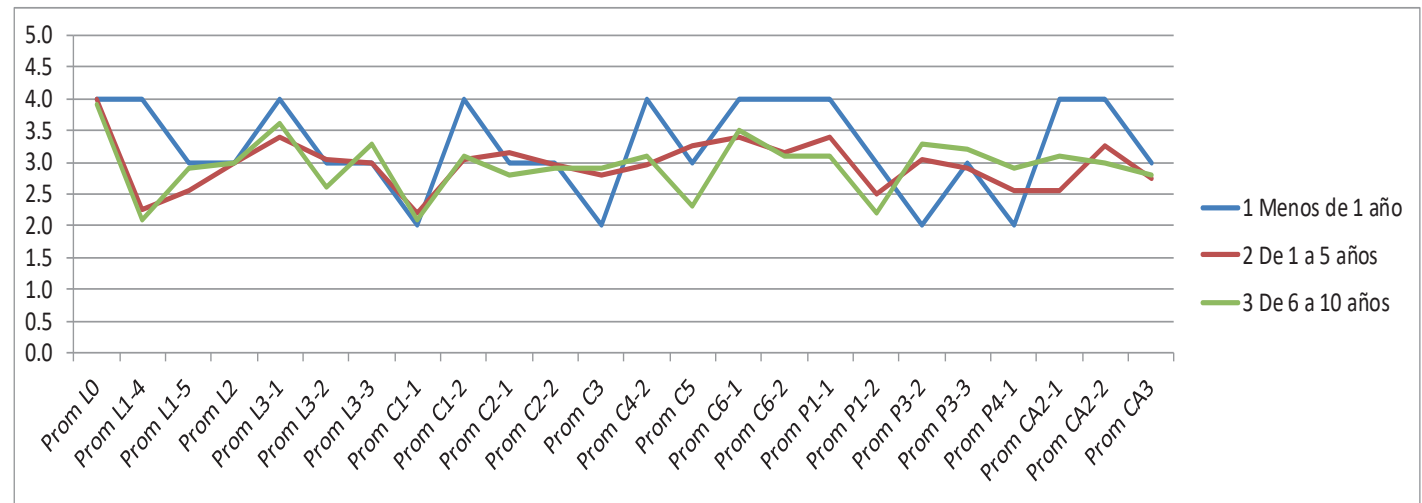

Figura 5. Valoración por antigüedad en el puesto. Fuente: elaboración propia.

Tabla 3. Fiabilidad del cuestionario para empleados.

\begin{tabular}{|l|c|c|c|}
\hline Dimensión o variable & Preguntas que se mantienen & $\alpha$ de Cronbach & Preguntas eliminadas \\
\hline Liderazgo en seguridad & L0 L1_4 L1_5 L2 L3_1 L3_2 & 0,798 & -- \\
\hline Comunicación efectiva bidireccional & $\begin{array}{c}\text { C1_1C1_2 C2_1 C2_2 C3 } \\
\text { C4_2 C5 C6_1 C6_2 }\end{array}$ & 0,881 & ---- \\
\hline $\begin{array}{l}\text { Participación del personal en la construcción de la } \\
\text { seguridad }\end{array}$ & P1_1 P1_2 P3_2 P3_3 P4_1 & 0,821 & ---- \\
\hline Existencia de una cultura de aprendizaje continuo & CA2_1 CA2_2 CA3 & 0,719 & CA1 CA4_1 CA4_5 CA4_6 \\
\hline Actitud hacia la culpa & & No covaría & A2 A3 A4 A5 \\
\hline Total & $\mathbf{2 4}$ & $\mathbf{0 , 9 4 4}$ & $\mathbf{8}$ \\
\hline
\end{tabular}

Fuente: elaboración propia. 
En el cuestionario complementario aplicado a directivos también se realizó evaluación de la fiabilidad; y, coincidentemente con el de los empleados, hubo poca consistencia interna en los indicadores de la variable: actitud hacia la culpa. La tabla 4 incluye el detalle de las preguntas a mantener y eliminar. EI coeficiente alfa de Cronbach final fue 0,913.

Nota: incluye información complementaria para evaluar la fiabilidad del cuestionario para empleados (herramienta diseñada).

\section{Análisis de la correlación}

La correlación resultó en un coeficiente de determinación igual a 99,5\%, el cual indica un fuerte ajuste que explica la variable dependiente por los cuatro factores propuestos, luego de eliminar la variable: actitud hacia la culpa. Se alcanzó la correlación en los 24 factores. Los resultados están expresados en las tablas 5 y 6 .

El valor $p=0,000$ en la tabla 7 , que se muestra más adelante, indica que el modelo es válido para las cuatro variables evaluadas.

Finalmente, se llegó a establecer los coeficientes del modelo que explican la dependencia de Cultura de Seguridad respecto de las cuatro variables ya indicadas; estos coeficientes están incluidos en la tabla 8.

Tabla 4. Fiabilidad del cuestionario para directivos.

\begin{tabular}{|l|c|c|c|}
\hline Dimensión o variable & Preguntas que se mantienen & $\alpha$ de Cronbach & Preguntas eliminadas \\
\hline Liderazgo en seguridad & L1_1 L1_2 L1_3 L3_1 & 0,790 & L2 L3_3 \\
\hline Comunicación efectiva & C4-1 C5 & 0,848 & -- \\
\hline $\begin{array}{l}\text { Participación del personal en la construcción de la } \\
\text { seguridad }\end{array}$ & $\begin{array}{r}\text { P2 P3-1 } \\
\text { P4-2 }\end{array}$ & 0,947 & --- \\
\hline Existencia de una cultura de aprendizaje continuo & $\begin{array}{c}\text { CA2-2 CA3 CA4-1 } \\
\text { CA4-2 CA4-3 CA4-4 }\end{array}$ & 0,801 & A1 \\
\hline Actitud hacia la culpa & & ---- & A2 \\
\hline FINAL & $\mathbf{1 5}$ & $\mathbf{0 , 9 1 3}$ & $\mathbf{4}$ \\
\hline
\end{tabular}

Fuente: elaboración propia.

Tabla 5. Correlaciones.

\begin{tabular}{|c|c|c|}
\hline & & CULTURA_DE_SEGURIDAD \\
\hline \multirow{2}{*}{ CULTURA_DE_SEGURIDAD } & Correlación de Pearson & 1 \\
\hline & $\mathrm{N}$ & 31 \\
\hline \multirow{3}{*}{ LIDERAZGO } & Correlación de Pearson & 0,915 \\
\hline & Sig. (bilateral) & 0,000 \\
\hline & $\mathrm{N}$ & 31 \\
\hline \multirow{3}{*}{ COMUNICACIÓN } & Correlación de Pearson & 0,944 \\
\hline & Sig. (bilateral) & 0,000 \\
\hline & $\mathrm{N}$ & 31 \\
\hline \multirow{3}{*}{ PARTICIPACIÓN } & Correlación de Pearson & 0,945 \\
\hline & Sig. (bilateral) & 0,000 \\
\hline & $\mathrm{N}$ & 31 \\
\hline \multirow{3}{*}{ CULTURA_APRENDIZAJE } & Correlación de Pearson & 0,870 \\
\hline & Sig. (bilateral) & 0,000 \\
\hline & $\mathrm{N}$ & 31 \\
\hline
\end{tabular}

Fuente: elaboración propia.

Tabla 6. Resumen del modelo.

\begin{tabular}{|c|c|c|c|c|}
\hline Modelo & $\mathbf{R}$ & $\mathbf{R}$ cuadrado & R cuadrado ajustado & Error estándar de la estimación \\
\hline 1 & $0,997^{\text {a }}$ & 0,995 & 0,994 & 0,34191 \\
\hline
\end{tabular}

Fuente: elaboración propia.

a. Predictores: (constante), CULTURA_APRENDIZAJE, PARTICIPACIÓN, LIDERAZGO, COMUNICACIÓN. 
Tabla 7. Anova .

\begin{tabular}{|c|l|c|c|c|c|c|}
\hline \multicolumn{2}{|c|}{ Modelo } & Suma de cuadrados & Grados de libertad & Media cuadrática & F & Sig. \\
\hline \multirow{4}{*}{1} & Regresión & 543,748 & 4 & 135,937 & 1154,173 & $0,000^{\mathrm{b}}$ \\
\cline { 2 - 7 } & Residuo & 3,062 & 26 & 0,118 & & \\
\cline { 2 - 7 } & Total & 546,810 & 30 & & & \\
\hline
\end{tabular}

Fuente: elaboración propia.

a. Variable dependiente: CULTURA_DE_SEGURIDAD.

b. Predictores: (constante), CULTURA_APRENDIZAJE, LIDERAZGO, COMUNICACIÓN, PARTICIPACIÓN.

Tabla 8. Coeficientes del modelo.

\begin{tabular}{|c|c|c|c|c|c|c|}
\hline \multicolumn{7}{|c|}{ Coeficientes $^{a}$} \\
\hline & \multirow{2}{*}{ Modelo } & \multicolumn{2}{|c|}{ Coeficientes no estandarizados } & \multirow{2}{*}{$\begin{array}{c}\text { Coeficientes estandarizados } \\
\text { Beta }\end{array}$} & \multirow{2}{*}{$\mathbf{t}$} & \multirow{2}{*}{ Sig. } \\
\hline & & B & Error estándar & & & \\
\hline \multirow{5}{*}{1} & (Constante) & 0,591 & 0,289 & & 2,047 & 0,051 \\
\hline & LIDERAZGO & 0,226 & 0,022 & 0,285 & 10,117 & 0,000 \\
\hline & COMUNICACIÓN & 0,248 & 0,020 & 0,375 & 12,090 & 0,000 \\
\hline & PARTICIPACIÓN & 0,285 & 0,031 & 0,304 & 9,080 & 0,000 \\
\hline & CULTURA_APRENDIZAJE & 0,185 & 0,048 & 0,106 & 3,826 & 0,001 \\
\hline
\end{tabular}

Fuente: elaboración propia.

a. Variable dependiente: CULTURA_DE_SEGURIDAD.

\section{Modelo:}

$\mathrm{Y}=0,591+0,226 \mathrm{X}_{1}+0,248 \mathrm{X}_{2}+0,285 \mathrm{X}_{3}+0,185 \mathrm{X}_{4}$

- $\mathrm{X}_{1}$ : Liderazgo en seguridad.

- $\mathrm{X}_{2}$ : Comunicación efectiva bidireccional.

- $\mathrm{X}_{3}$ : Participación del personal en la construcción de la seguridad.

- $\mathrm{X}_{4}$ : Existencia de una cultura de aprendizaje continuo.

- Y: Cultura de Seguridad.

\section{DISCUSIÓN}

\section{Identificación de los factores que condicionan la Cultura de Seguridad}

Se confirmó la incidencia, en la Cultura de Seguridad, para cuatro de los cinco factores propuestos: liderazgo en seguridad, comunicación efectiva bidireccional, participación del personal en la construcción de la seguridad y existencia de una cultura de aprendizaje continuo; no se confirmó la incidencia de la quinta variable: actitud hacia la culpa. Por lo tanto, se coincide con Carvalho (2011) en señalar la importancia del liderazgo y la comunicación.

\section{Evaluación de los factores que condicionan la Cultura de Seguridad}

Fue posible establecer una valoración de la Cultura de Seguridad al asociar los factores a 32 indicadores de desempeño, con 5 niveles de progreso, y someterlos a evaluación con el instrumento diseñado bajo la forma de un cuestionario.

El instrumento final obtenido incluye 24 indicadores validados, referidos a los 4 factores indicados.

\section{Análisis de la fiabilidad}

El instrumento final (cuestionario) presenta una fiabilidad de 0.944 para cada una de las dimensiones: liderazgo en seguridad, comunicación efectiva bidireccional, participación del personal en la construcción de la seguridad y existencia de una cultura de aprendizaje continuo, con coeficientes de 0.798 , $0.881,0.821$ y 0.719 , respectivamente.

Para la variable: existencia de una cultura de aprendizaje continuo, cuatro de los siete factores presentaron poca fiabilidad, pudiendo explicarse por la incipiente gestión de las observaciones de seguridad y por el poco involucramiento de los trabajadores en las investigaciones de incidentes. 
La fiabilidad limitada en el factor: actitud hacia la culpa tendría su origen en algunas facetas de la cultura local, correspondiente a represión, castigo y culpa, traducido en una gran variación en las respuestas al cuestionario de trabajadores, a diferencia de las respuestas del cuestionario para directivos y con la información obtenida de la documentación y entrevistas desarrolladas.

\section{Necesidad de un enfoque multimétodo}

El enfoque multimétodo consiste en revisar registros y documentación específica en seguridad, visitar el entorno de trabajo y llevar a cabo entrevistas directas con los trabajadores, así como el emplear un cuestionario para obtener las apreciaciones de la gestión en seguridad. Este enfoque debe ser el que se conduzca durante la aplicación del instrumento, ya que brinda mayor conocimiento de la organización, el sistema de trabajo y el estado real de los diferentes aspectos en seguridad. La subjetividad queda reducida al analizar los resultados y se tendrían mayores sustentos para explicar la validez de la data.

\section{Ventajas del instrumento diseñado}

El instrumento desarrollado resulta de gran utilidad en la medida que:

- Contribuye de manera rápida a la identificación de oportunidades de mejora en la gestión de seguridad.

- Ayuda a identificar las brechas en la percepción de la seguridad.

- $\quad$ Permite proponer, de manera formal y en el corto plazo, acciones de mejora en seguridad que sean menos empíricas y más efectivas.

- Proporciona una base de referencia para monitorear el impacto de las acciones diseñadas para mejorar la seguridad.

- Puede emplearse periódicamente para verificar avances en seguridad, con retroalimentación objetiva, propendiendo a la mejora continua.

- Brinda la oportunidad de comparar los resultados entre empresas (benchmarking).

\section{CONCLUSIONES}

- Se confirmó que la Cultura de Seguridad es influenciada por cuatro factores: liderazgo en seguridad, comunicación efectiva bidireccional, participación del personal en la construcción de la seguridad y existencia de una cultura de aprendizaje continuo.

- Quedó elaborada una herramienta para la valoración local de cada uno de los factores indicados.

\section{RECOMENDACIONES}

- A partir del instrumento resultante del presente trabajo, se recomienda el desarrollo de otras herramientas de gestión que tomen en cuenta los factores y variables ya confirmadas.

- Se recomienda verificar la validez del instrumento desarrollado en empresas de otros rubros, para confirmar su aplicabilidad general.

- Es necesario realizar una discusión con representantes de la dirección o gerencia de seguridad, de modo que se verifiquen y expliquen las respuestas obtenidas, se aclaren las apreciaciones que dejaron las entrevistas, visita a instalaciones y revisión de la documentación. No es posible iniciar un análisis sin considerar las experiencias internas de la organización. Las verificaciones de fiabilidad y validez del instrumento solo podrían plantearse en etapa posterior al desarrollo de las actividades indicadas.

- Se recomienda, como parte de un trabajo de investigación complementario, la validación de los once factores aplicables a los directivos.

\section{REFERENCIAS BIBLIOGRÁFICAS}

[1] Bjørneide, C. (2003). Tool to be used to survey and improve Safety Culture in the European railway industry. Recuperado de https://www. sintef.no/globalassets/upload/teknologi_og_ samfunn/sikkerhet-og-palitelighet/prosjekter/ safeculture/hovedoppgave_camillabergersen. pdf.

[2] Carvalho, R. J. (2011). Análise dos fatores intervenientes na ocorrência de quaseacidentes: um estudo de caso em uma equipe do departamento de logística de uma indústria química. (Tesis de doctorado). Universidade Estadual Paulista, São Paulo. Recuperado de https://repositorio.unesp.br/bitstream/ handle/11449/103060/carvalho_rj_dr_guara. pdf? sequence=1\&isAllowed=y.

[3] Congreso de la República (20 de agosto del 2011). Ley 29783. Ley de Seguridad y Salud en el Trabajo. Diario Oficial El Peruano, Normas Legales 448694-448706. 
[4] Cooper, M. D. (2000). Towards a model of safety culture. Safety Science, 36, 111-136. Recuperado de http://www.behavioral-safety. com/articles/Towards_a_model_of_safety_ culture.pdf.

[5] Gadd, S. (2002). Safety Culture: a review of the literature. Sheffield, Reino Unido: Health \& Safety Laboratory. Recuperado de http://www. hse.gov.uk/research/hsl_pdf/2002/hsl02-25.pdf.

[6] Grillo, N. (2013). Construcción y validación de una herramienta de gestión para evaluar la cultura de seguridad en entornos industriales. (Tesis de doctorado). Universitat Ramon Llull, Barcelona. Recuperado de https://www. tesisenred.net/handle/10803/119823\#page=1.

[7] Guldenmund, F. W. (2000). The nature of Safety Culture: a review of theory and research. Safety Science, 34(1-2), 215-257. Recuperado de https://www.sciencedirect.com/science/article/ pii/S092575350000014X.

[8] Guldenmund, F. W. (2010). Understanding and exploring Safety Culture. Oisterwijk, Netherlands: Uitgeverij Boxpress. Recuperado de https://repository.tudelft.nl/islandora/ object/uuid:30fb9f1c-7daf-41dd-8a5cb6e3acfe0023?collection =research.

[9] Human Engineering for the Health and Safety Executive (2005a). Development and validation of the HMRI safety culture inspection toolkit. Research report 365. Norwich, Reino Unido: HSE Books. Recuperado de http://www.hse. gov.uk/research/rrpdf/rr365.pdf.

[10] Human Engineering for the Health and Safety Executive (2005b). A review of safety culture and safety climate literature for the development of the safety culture inspection toolkit. Research report 367. Norwich, Reino Unido: HSE Books. Recuperado de http://www. hse.gov.uk/research/rrpdf/rr367.pdf.

[11] International Association of Oil \& Gas Producers (2010). A guide to selecting appropriate tools to improve HSE culture. Londres, Reino Unido: OGP Publications. Recuperado de http://www. learnfromaccidents.com.gridhosted.co.uk/ images/uploads/OGP_435_Selecting_the right_tool.pdf.
[12] International Nuclear Safety Advisory Group (1991). Safety Culture. A report by International Nuclear Safety Advisory Group. Safety Series 75-INSAG-4. Viena, Austria: IAEA. Recuperado de https://www-pub.iaea.org/MTCD/ publications/PDF/Pub882_web.pdf.

[13] International Nuclear Safety Advisory Group (1992). The Chernobyl Accident-Updating of INSAG-1. Safety Series 75-INSAG-7. Viena, Austria: IAEA. Recuperado de https://www-pub. iaea.org/MTCD/publications/PDF/Pub913e_ web.pdf.

[14] International Nuclear Safety Advisory Group (2002). Key practical issues in strengthening Safety Culture. Safety Series INSAG-15. Viena, Austria: IAEA. Recuperado de https:// www-pub.iaea.org/MTCD/Publications/PDF/ Pub1137_scr.pdf.

[15] Ministerio de Trabajo y Promoción de Empleo (25 de abril del 2012). Reglamento de la Ley de Seguridad y Salud en el Trabajo, Decreto Supremo N. ${ }^{\circ}$ 005-2012-TR. Diario Oficial El Peruano, Normas Legales 464861-454880.

[16] Morales-Vallejo P. (2011). Guía para construir cuestionarios y escalas de actitudes. Guatemala: Universidad Rafael Landívar. Recuperado de http://www.upcomillas. es/personal/peter/otrosdocumentos/ Guiaparaconstruirescalasdeactitudes.pdf.

[17] The Keil Centre for the Health and Safety Executive (2000). Safety culture maturity model. Offshore technology report 2000/049. Norwich, Reino Unido: HSE Books. Recuperado de http://www.hse.gov.uk/research/otopdf/2000/ oto00049.pdf.

[18] The Rt Hon Lord Cullen PC (2001). The Ladbroke Grove Rail Inquiry. Part 2 report. Norwich, Reino Unido: HSE Books. Recuperad de https:// orr.gov.uk/_data/assets/pdf_file/0020/5663/ incident-ladbrokegrove-lgri2.pdf. 


\section{Designing a management tool to assess safety culture in the workplace}

José Luis RoJAS CASTRO FÉlix TiNOCo Ángeles ${ }^{2}$

\section{ABSTRACT}

The safety culture that prevails within an organization and the way in which the latter addresses and manages safety problems has a significant influence on the safetyrelated behavior of people in the workplace. For that reason, it is essential that every organization is able to identify and objectively evaluate the factors that influence safety culture.

This research paper seeks to identify the factors that affect safety culture and establish a qualitative rating scale for each. Consequently, the appropriate knowledge of each of these factors suggests more objective, accurate and effective safety actions. The review of prior objective European research led to the development of a proprietary methodology in order to design a tool that is applicable to the local environment that currently lacks one. The end result achieved was a questionnaire addressed to the workforce, which evaluated 32 out of 43 identified indicators that have a potential impact on safety culture, including the description of five levels of development for each indicator. Finally, the design of the tool to assess safety culture was validated and the incidence of four factors in safety culture was confirmed: leadership in safety, effective communication, participation of personnel in the construction of safety and existence of a continuous learning culture, which were associated with 24 indicators.

Keywords: Questionnaire; safety culture; leadership in safety; effective communication; participation of personnel; learning culture.

\section{INTRODUCTION}

The better an organization knows the factors that affect safety culture and their level of development, the better it will be able to propose safety actions that are more adapted to its reality, effective, use less time to achieve its goals, and direct its safety management system towards continuous improvement. This is required by the Occupational Safety and Health Act (Law No. 29783), in section 18 (Congreso de la República, 2011) and by the regulations of Law DS-005-2012-TR, section 26 (Ministerio de Trabajo y Promoción de Empleo, 2012).

The results obtained from the implementation of safety measures are not always consistent with the efforts made to do so, and only in a few organizations is a very positive change towards safety by workers achieved. In contrast, in most organizations, only small and very insignificant changes in safety occur, despite the fact that significant investments and resources are applied in many of them. This occurs because there is no formal knowledge and evaluation of the factors that influence safety culture, and because the actions proposed in safety management are made following the revision of accident rate indicators and compliance with work programs. They omit factors such as communication, participation and the commitment of workers to safety. The assessments are subjective and this is verifiable at the close of every work year, since many efforts are not aligned with the organizational context, expected progress is not achieved and even setbacks are reported.

\section{Previous studies of the research topic}

The review of the literature on the subject covers the last thirty years and is focused on the following key issues:

- What is measured: Safety culture, safety climate, organizational culture, attitude and/or behavior of people, behavioral factors, inter-organizational relationships.

1 Mechanical engineer and bachiller in Industrial Engineering from the Universidad Nacional Mayor de San Marcos. Currently working as teacher at the Centro Pre-universitario of the Pontificia Universidad Católica del Perú (PUCP) and as teaching assistant at the PUCP. E-mail: rojas.j@pucp.edu.pe

2 Master in Operations Management and Logistics Services from the Universidad Nacional Mayor de San Marcos. Currently working as an independent consultant. E-mail: tinocofelix@gmail.com 
- Criteria and/or indicators of assessment of safety culture: focused on discerning positive and negative characteristics.

- Safety culture assessment and measurement tools.

The research began with the review of compilations of studies developed regarding safety culture (Gadd, 2002; Human Engineering for the Health and Safety Executive, 2005b). Subsequently, documents containing concepts and definitions related to safety culture, safety climate and organizational culture were reviewed (Cooper, 2000; Guldenmund, $2000 \& 2010)$.

Likewise, documents were integrated with the aim of obtaining a better understanding of the factors that determine safety in an organization, since they were developed after the occurrence of major accidents, including the English railway system accident at Ladbroke, which resulted in a full investigation report (The Rt Hon Lord Cullen PC, 2001), and the accident at Chernobyl, which resulted in a review of the concept of safety culture and the factors influencing it (International Nuclear Safety Advisory Group, 1991).

It was also possible to review the document drafted by the International Atomic Energy Agency (1992), which listed the conditions and omissions at the time of the Chernobyl accident, which was the basis for the proposal of a questionnaire prepared by the International Nuclear Safety Advisory Group (2002), with questions addressed to various operational and administrative levels, aimed at assessing personal contributions to the improvement of safety culture.

In addition, reference was made to the work of Carvalho (2011), who identified organizational factors related to the occurrence of occupational accidents, including employee behavior, participatory management, the behavior of the safety department, risk perception, leadership, perception of justice and communication processes.

Furthermore, documents that proposed tools to assess safety culture and analyze the factors that influence it were also reviewed. One of these documents applied to the English railway sector was Human Engineering for the Health and Safety Executive (2005a), which was based on previously conducted studies and focus groups, resulting in a questionnaire tool with open and closed questions, and evidence points for each factor. A second document proposed by Grillo (2013) was aimed at companies in the chemical sector, which despite its complexity due to explanations with psychological approaches, details a validation of factors methodology using statistical tools in order to modify their grouping to achieve a very good correlation and reliability that allows for the comparison of levels of safety between groups within an organization. A third document, by Bjørneide (2003), concerns the proposal of a tool to assess safety culture in the European rail system using a questionnaire, whose main objective was to improve the safety culture by promoting collaborative group discussions and processes within and between organizations.

Finally, as a reference to the indicators of each of the safety factors, an Oil \& Gas Producers guide (2010) was reviewed in order to select tools for the improvement of the safety culture that was developed by oil producers, as well as a guide by Morales-Vallejo (2011) in order to draft a questionnaire, which was crucial in the creation of our own proposal.

\section{Applicability of existing instruments}

Although there are several tools to assess safety culture in other countries, it is not convenient to apply them directly to the local environment, since they are influenced by cultural, social and economic contexts, as well as by the culture developed in each work organization. Thus, it is appropriate to design an instrument to evaluate safety culture in the local environment, so that its use provides helpful results in order to promote the process of continuous improvement.

\section{MATERIALS Y METHODS}

\section{Method}

It is a quantitative, prospective, transversal, descriptive and explanatory study.

\section{Methodology for tool design}

Following the review of the aforementioned bibliography characterizing safety culture and previously-developed evaluation tools, a model was proposed that included five variables: leadership in security, effective two-way communication, staff participation in building safety, presence of a continuous learning culture and attitude towards blame. Each variable was analyzed in dimensions and sub-dimensions, defining performance indicators for each of the latter. The analysis of each indicator led to the generation of questions and five levels of development established for each indicator, resulting in the design of a questionnaire. 
To determine each level of development, a safety management reference framework was designed, identifying the following aspects:

- Planning and organization: What systems are in place?

- Control: Who is responsible?

- Effectiveness: How does it happen in practice?

- Information flow: What happens with the information gathered?

- Monitoring and review: Are results and actions measured?

Once development in each of these aspects began, the characteristics for each indicator were identified in five levels of progress, resembling this characterization to the level of maturity proposed for safety culture in England (The Keil Centre for the Health and Safety Executive, 2000) which identifies five levels of maturity: emerging, management, participation, cooperation and continuous improvement.

The performance indicators initially associated with five variables gave rise to 43 questions that were reorganized into six thematic scenarios, with the intention of facilitating their analysis and response by respondents. These were: security management, security observations, change management, transfer of information on shift duties, degraded situation and incident management. Of the 43 questions, 32 were applicable to the workforce and 19 to managers (of which 8 were common questions for workers and 11 corresponded to specific safety management skills).

The elaboration of a questionnaire with 32 questions for workers, which is the target audience, was completed. A contrast questionnaire with five general assessment questions was prepared for each variable.

The 19 questions applicable to management members provide complementary information, which supports the validation of what is reported by the target workforce.

\section{Population and sample}

The questionnaire is a tool directed at mining contractor companies which have implemented a yetto-be-certified safety management system based upon international guidelines such as OHSAS 18001; they also direct their efforts to improve safety, based on the management of accident factors (accident rates) and safety prevention campaigns. The main sample is comprised of the total population of workers in the maintenance service area of the Robocon Company (fifty people). In addition, 10 out of a total of 12 people were invited to respond the questionnaire with the intention of obtaining additional information on security from the management of the organization. Of the personnel invited, the questionnaires completed by workers with less than one year in the company were rejected, considering that they might lack sufficient knowledge of the organizational and safety culture in the company (see Table 1).

Data gathering: main, complementary and contrast questionnaires

The different questionnaires applied to workers and managers were previously submitted to senior management for their knowledge and approval. On the one hand, the questionnaire prepared for managers was prepared electronically and made available for completion by means of Socrative. Only two of the twelve executives, the manager and the deputy security manager, were excluded. On the other hand, the questionnaire prepared for workers was submitted in written form, accompanied by a reply form. In addition, a slide presentation was prepared for questions and answer choices, which was presented and explained by a facilitator. In this way, a correct understanding of each question and best answer choice was encouraged. Finally, a written contrast questionnaire (general assessment of safety culture) with five questions evaluating the factors proposed as variables that determine the safety culture was taken.

Table 1. Sample size.

\begin{tabular}{|l|l|l|l|}
\hline \multicolumn{1}{|c|}{ Sample } & Workers & Management & Total \\
\hline Total population & 50 & 12 & 62 \\
\hline Invited population & 50 & 10 & 60 \\
\hline Sample & 50 & 10 & 60 \\
\hline Sample data producer & $\mathbf{3 1}$ & $\mathbf{7}$ & $\mathbf{3 8}$ \\
\hline Sample data producer $\%$ & $62 \%$ & $70 \%$ & $63.3 \%$ \\
\hline
\end{tabular}

Source: Prepared by the authors.

\section{RESULTS OF THE STUDY APPLIED IN A SPE-} CIFIC ORGANIZATION

The main study involved 31 employees, including four division heads (12.9\%), six supervisors (19.35\%) and 21 operators and laborers (67.7\%). In addition, seven managers participated in the follow-up study. 


\section{General assessment according to age, training and seniority}

Similar rating of safety culture according to age, training and seniority was observed (see Figure 1):

\section{Data collection: additional general employee in- formation}

The questionnaire for employees provided general information concerning training and job category, which is included in Table 2:

Information was obtained from the responses according to the age of the workers, training, seniority in the organization and in position, which is detailed by question in Figures 2, 3, 4 and 5, respectively. The aim was to recognize differences according to the group chosen.

\section{Rating by age}

Rating is similar, except for people who are 41 to 50 years old (4 cases), who differ by a lower score than the rest (27 cases).

\section{Rating by training}

Figure 3 shows that the rating is broadly similar, with one exception. This case corresponds to an individual with a postgraduate degree who scored lower on fifteen questions (two points less than the average).

\section{Rating by seniority in the organization}

Figure 4 shows a similar overall rating, except for one individual with between 11 to 20 years with the company (the longest-serving employee), who scored higher than the average on thirteen questions.

\section{Rating by seniority in position}

Figure 5 confirms that the rating for each question is broadly similar and does not depend on seniority in position.

\section{ANALYSIS OF COLLECTED DATA}

The validation of the data collected regarding the safety culture indicators began with the evaluation of the reliability of the questionnaires for workers and executives, excluding those with low reliability in subscale analysis (at variable level).

The concurrent validation was then carried out by integrating the information resulting from the review of specific documentation on safety, visits to the working environment and the development of direct interviews with workers and managers, as well as the analysis of the results contained in the

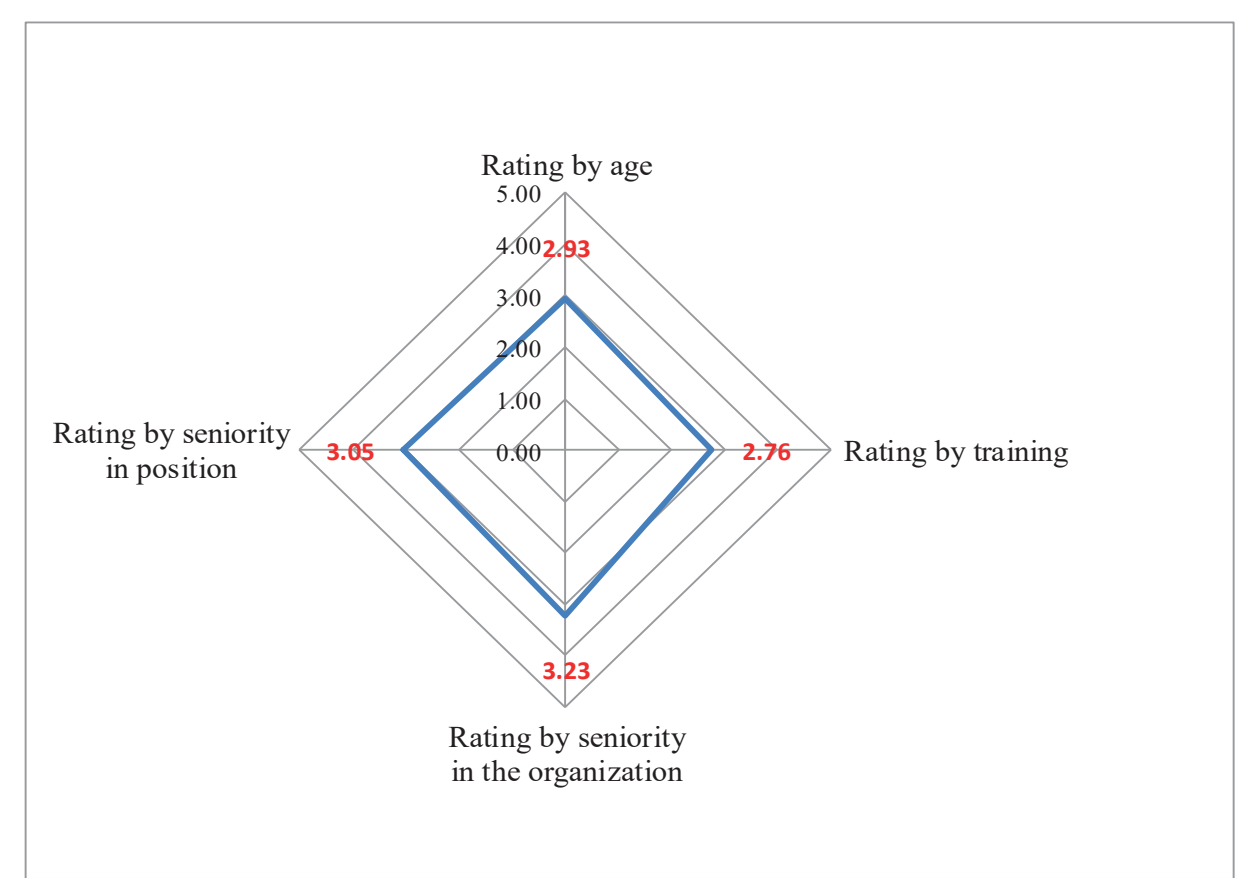

Figure 1. General assessment according to age, training and seniority. Source: Prepared by the authors. 
Table 2. Training and job category.

\begin{tabular}{|l|c|c|c|c|}
\hline Sample & Division heads & Supervisor & Laborers & Percentage \\
\hline Postgraduate & & 1 & & $3.2 \%$ \\
\hline University graduate & 2 & 1 & 4 & $22.6 \%$ \\
\hline Incomplete technical or university training & 2 & 3 & 11 & $51.6 \%$ \\
\hline $\begin{array}{l}\text { Complete high school education or incomplete } \\
\text { technical education }\end{array}$ & & 1 & 4 & $16.1 \%$ \\
\hline $\begin{array}{l}\text { Complete elementary education or incomplete } \\
\text { high school education }\end{array}$ & & & 2 & $6.5 \%$ \\
\hline Total & 4 & 6 & 21 & $100 \%$ \\
\hline
\end{tabular}

Source: Prepared by the authors.

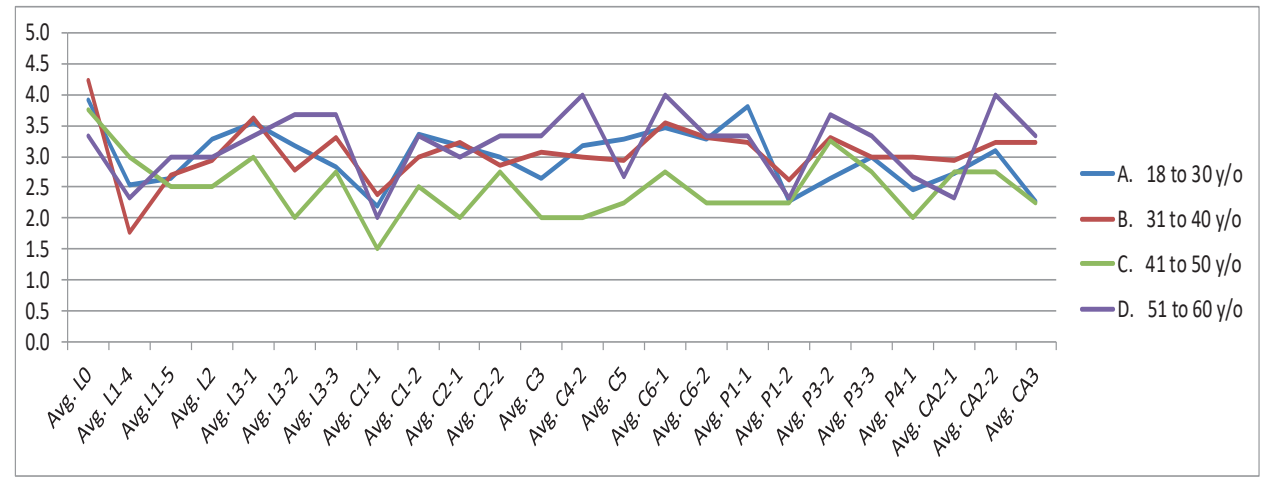

Figure 2. Rating by age.

Source: Prepared by the authors.

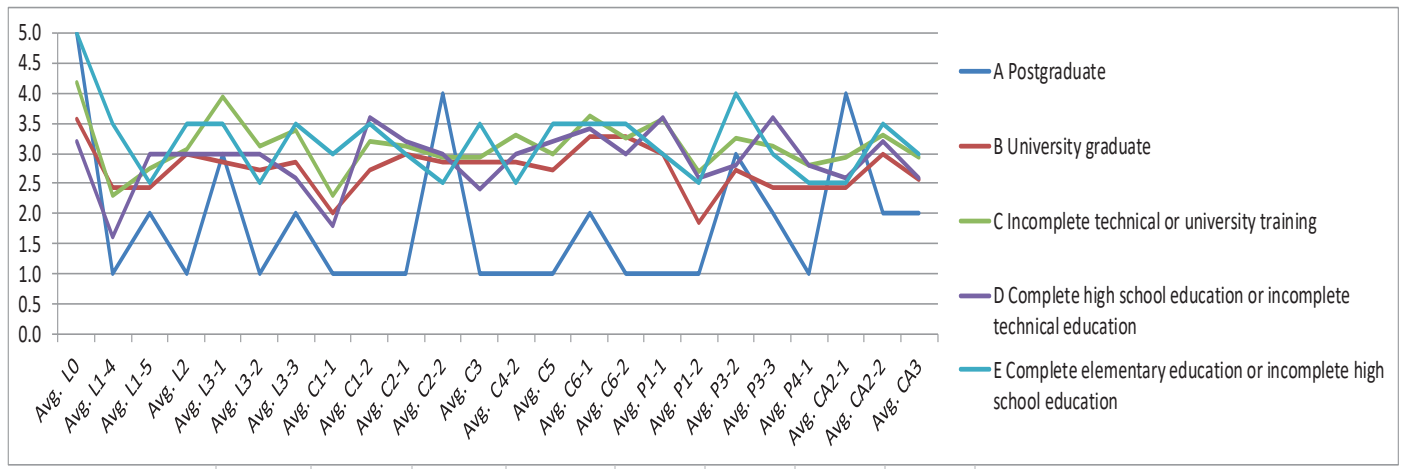

Figure 3. Rating by age.

Source: Prepared by the authors.

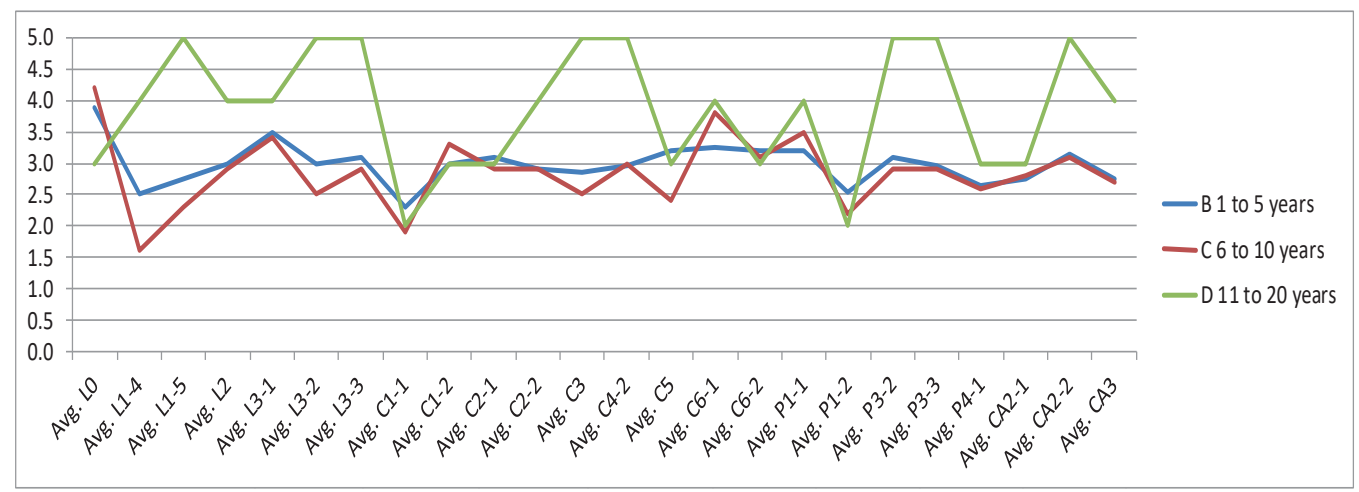

Figure 4. Rating by seniority in the organization.

Source: Prepared by the authors. 
questionnaires for managers and with the contrast questionnaire.

Finally, the validation of the construct was carried out through the study of correlations and regression.

\section{Analysis of the reliability and validity of the construct}

From the analysis of the 32 indicators in the questionnaire designed for workers it was possible to confirm reliability in 24 , corresponding to the first four variables: leadership in safety, effective twoway communication, staff participation in building safety and existence of a culture of continuous learning. The Cronbach's alpha coefficient for variable "attitude towards blame" did not exceed the minimum value established, indicating little internal consistency in the components. Therefore, only the first four variables were tested for correlation.

Table 3 includes the questions that remained and those that were removed from the questionnaire to obtain the highest Cronbach alpha coefficient (0.944).
The complementary questionnaire addressed to managers was also tested for reliability; coincidentally with the one addressed to workers, there was little internal consistency in the indicators of the variable "attitude towards blame". Table 4 includes the detail of the questions to be maintained and removed. The final Cronbach's alpha coefficient was 0.913 .

Note: includes supplementary information to assess reliability of the questionnaire addressed to workers (designed instrument).

\section{Correlation analysis}

The correlation resulted in a $99.5 \%$ coefficient of determination, which, after eliminating the variable "attitude towards blame", indicates a strong fit that explains the dependency of the variable on the four factors proposed. Correlation was achieved in all 24 factors. The results are expressed in Tables 5 and 6.

In Table 7 shown below, the p-value equal to 0.000 indicates that the model is valid for the four variables evaluated.

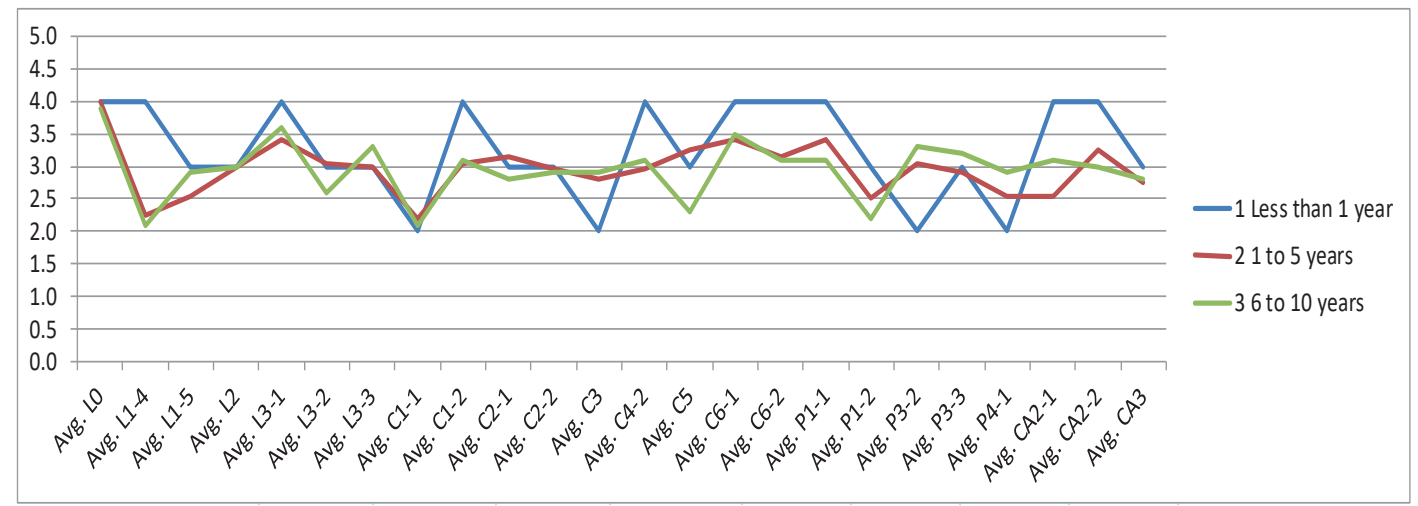

Figure 5. Rating by seniority in position. Source: Prepared by the authors.

Table 3. Reliability of the questionnaire designed for workers.

\begin{tabular}{|l|c|c|c|}
\hline Dimension or variable & Remaining questions & Cronbach's $\alpha$ & Deleted questions \\
\hline Leadership in safety & L0 L1_4 L1_5 L2 L3_1 L3_2 & 0.798 \\
\hline Effective two-way communication & C1_1 C1_2 C2_1 C2_2 C3 & C4_2 C5 C6_1 C6_2 & 0.881 \\
\hline Staff participation in building safety & P1_1 P1_2 P3_2 P3_3 P4_1 & 0.821 & 0.719 \\
\hline Existence of a culture of continuous learning & CA2_1 CA2_2 CA3 & No covariance \\
\hline Attitude towards blame & & A2 A3 A4 A5 \\
\hline Total & 24 & 8 & ----- \\
\hline
\end{tabular}

Source: Prepared by the authors. 
Finally, the coefficients of the model that explain the dependence of safety culture on the four previously-indicated variables were established; these coefficients are included in Table 8.

\section{Model:}

$Y=0,591+0,226 X_{1}+0,248 X_{2}+0,285 X_{3}+0,185 X_{4}$

- $\quad \mathrm{X}_{1}$ : Leadership in safety.

- $\mathrm{X}_{2}$ : Effective two-way communication.

- $\quad \mathrm{X}_{3}$ : Staff participation in building safety.

- $\mathrm{X}_{4}$ : Existence of a culture of continuous learning.
- Y: Safety culture.

\section{DISCUSSION}

\section{Identification of the factors that condition safety culture}

The incidence in safety culture was confirmed for four of the five proposed factors: leadership in security, effective two-way communication, staff participation in building safety and a culture of continuous learning. The incidence of the fifth variable "attitude towards blame" was not confirmed. Therefore, results agree with Carvalho (2011) in emphasizing the importance of leadership and communication.

Table 4. Reliability of the questionnaire designed for managers.

\begin{tabular}{|c|c|c|c|}
\hline Dimension or variable & Remaining questions & Cronbach's $\alpha$ & Deleted questions \\
\hline Leadership in safety & L1_1 L1_2L1_3 L3_1 & 0.790 & L2 L3_3 \\
\hline Effective two-way communication & C4-1 C5 & 0.848 & ----- \\
\hline Staff participation in building safety & $\begin{array}{c}\text { P2 P3-1 } \\
\text { P4-2 }\end{array}$ & 0.947 & ----- \\
\hline Existence of a culture of continuous learning & $\begin{array}{cc}\text { CA2-2 CA3 } & \text { CA4-1 } \\
\text { A4-2 CA4-3 } & \text { CA4-4 }\end{array}$ & 0.801 & \\
\hline Attitude towards blame & & --- & $\mathrm{A} 1$ \\
\hline TOTAL & 15 & 0.913 & 4 \\
\hline
\end{tabular}

Source: Prepared by the authors.

Table 5. Correlations.

\begin{tabular}{|l|c|c|}
\hline \multirow{2}{*}{ CULTURE_OF_SAFETY } & & CULTURE_OF_SAFETY \\
\hline \multirow{3}{*}{ LEADERSHIP } & Pearson's correlation & 1 \\
\cline { 2 - 3 } & $\mathrm{N}$ & 31 \\
\hline \multirow{3}{*}{ COMMUNICATION } & Pearson's correlation & 0.915 \\
\cline { 2 - 3 } & Sig. (2-tailed) & 31 \\
\cline { 2 - 3 } & $\mathrm{N}$ & 0.944 \\
\hline \multirow{3}{*}{ PARTICIPATION } & Pearson's correlation & 0.000 \\
\cline { 2 - 3 } & Sig. (2-tailed) & 31 \\
\cline { 2 - 3 } & $\mathrm{N}$ & 0.945 \\
\hline \multirow{3}{*}{ CULTURE_OF_LEARNING } & Pearson's correlation & 0.000 \\
\cline { 2 - 3 } & Sig. (2-tailed) & 31 \\
\cline { 2 - 3 } & $\mathrm{N}$ & 0.870 \\
\cline { 2 - 3 } & Pearson's correlation & 0.000 \\
\cline { 2 - 3 } & Sig. (2-tailed) & 31 \\
\hline
\end{tabular}

Fuente: elaboración propia.

Table 6. Summary of the model.

\begin{tabular}{|c|c|c|c|c|}
\hline Modelo & $\mathbf{R}$ & $\mathbf{R}$ cuadrado & R cuadrado ajustado & Error estándar de la estimación \\
\hline 1 & $0,997^{\text {a }}$ & 0,995 & 0,994 & 0,34191 \\
\hline
\end{tabular}

Source: Prepared by the authors.

a. Predictors: (constant), CULTURE_OF_LEARNING, PARTICIPATION, LEADERSHIP, COMMUNICATION. 
Table 7. Anova ${ }^{\text {. }}$

\begin{tabular}{|l|l|c|c|c|c|c|}
\hline \multicolumn{2}{|l|}{ Model } & Sum of squares & Degrees of freedom & Mean square & F & Sig. \\
\hline \multirow{4}{*}{1} & Regression & 543.748 & 4 & 135.937 & 1154.173 & $0.000^{\mathrm{b}}$ \\
\cline { 2 - 7 } & Residual & 3.062 & 26 & 0.118 & & \\
\cline { 2 - 7 } & Total & 546.810 & 30 & & & \\
\hline
\end{tabular}

Source: Prepared by the authors.

a. Dependent variable: CULTURE_OF_SAFETY.

b. Predictors: (constant), CULTURE_OF_LEARNING, LEADERSHIP, COMMUNICATION, PARTICIPATION.

Table 8. Coefficients of the model.

\begin{tabular}{|c|c|c|c|c|c|c|}
\hline \multicolumn{7}{|c|}{ Coefficients $^{a}$} \\
\hline & \multirow{2}{*}{ Model } & \multicolumn{2}{|c|}{ Unstandardized coefficients } & \multirow{2}{*}{$\begin{array}{c}\text { Standardized coefficients } \\
\text { Beta }\end{array}$} & \multirow{2}{*}{$\mathbf{t}$} & \multirow{2}{*}{ Sig. } \\
\hline & & B & Standard error & & & \\
\hline \multirow{5}{*}{1} & (Constant) & 0.591 & 0.289 & & 2.047 & 0.051 \\
\hline & LEADERSHIP & 0.226 & 0.022 & 0.285 & 10.117 & 0.000 \\
\hline & COMMUNICATION & 0.248 & 0.020 & 0.375 & 12.090 & 0.000 \\
\hline & PARTICIPATION & 0.285 & 0.031 & 0.304 & 9.080 & 0.000 \\
\hline & CULTURE_OF_LEARNING & 0.185 & 0.048 & 0.106 & 3.826 & 0.001 \\
\hline
\end{tabular}

Source: Prepared by the authors.

a. Dependent variable: CULTURE_OF_SAFETY.

\section{Evaluation of the factors that condition safety culture}

It was possible to establish a rating of safety culture by associating the factors with 32 performance indicators, with 5 levels of progress, and assess them using the instrument designed as a questionnaire.

The final instrument includes 24 validated indicators, associated with the 4 indicated factors.

\section{Reliability analysis}

The final instrument (questionnaire) has a reliability coefficient of 0.944 for each of the dimensions: leadership in safety, effective two-way communication, staff participation in building security and existence of a culture of continuous learning, with coefficients of $0.798,0.881,0.821$ and 0.719 , respectively.

For variable existence of a culture of continuous learning, four of the seven factors had low reliability, which can be explained by the poor management of safety observations and by little involvement of workers in incident investigations.

The limited reliability in the factor "attitude towards blame" originates in some aspects of the local culture, corresponding to repression, punishment and blame, translated into a great variation in the responses to the questionnaire addressed to workers, as opposed to the answers to the questionnaire for managers and with the information obtained from the documentation and interviews conducted.

\section{Need for a multi-method approach}

The multi-method approach consists of reviewing safety records and specific documentation, visiting the working environment and conducting direct interviews with workers, as well as using a questionnaire to obtain safety management assessments. This approach should be used during the implementation of the instrument, since it provides greater knowledge of the organization, the work system and the actual state of the different aspects of safety. Subjectivity is reduced when analyzing the results and there would be more evidence to explain the validity of the data.

\section{Advantages of the instrument}

The instrument developed is of great use as it:

- Contributes to the prompt identification of improvement opportunities in safety culture management.

- Helps identify gaps in the perception of safety.

- Makes possible the proposal, both formally and in the short term, of less empirical and more effective improvement measures of safety. 
- Provides a baseline to monitor the impact of measures designed to improve safety.

- $\quad$ Can be used periodically to verify advances in safety culture, with objective feedback, aiming at continuous improvement.

- Offers the opportunity to compare results between companies (benchmarking).

\section{CONCLUSIONS}

- It was confirmed that safety culture is influenced by four factors: leadership in safety, effective two-way communication, staff participation in building safety and existence of a culture of continuous learning.

- A tool for local assessment of each of the above factors was developed.

\section{RECOMENDATIONS}

- Based upon the instrument resulting from this study, it is recommended that the other management tools that take into account the already-confirmed factors and variables be developed.

- It is recommended that the validity of the developed instrument be verified in companies in other sectors, in order to confirm its general applicability.

- It is necessary to discuss the matter with representatives of the management or security management areas, so that the responses obtained can be verified and explained, and the opinions of respondents, visit to facilities and review of documentation can be clarified. It is not possible to begin an analysis without considering the internal experiences of the organization. Verification of the reliability and validity of the instrument could only be considered at a stage subsequent to the development of the activities indicated.

- As part of complementary research work, it is recommended that the 11 factors applicable to managers be validated.

\section{REFERENCES}

[1] Bjørneide, C. (2003). Tool to be used to survey and improve Safety Culture in the European railway industry. Retrieved from https://www. sintef.no/globalassets/upload/teknologi_og_ samfunn/sikkerhet-og-palitelighet/prosjekter/ safeculture/hovedoppgave_camillabergersen. pdf.

[2] Carvalho, R. J. (2011). Análise dos fatores intervenientes na ocorrência de quaseacidentes: um estudo de caso em uma equipe do departamento de logística de uma indústria química. (Doctoral thesis). Universidade Estadual Paulista, São Paulo. Retrieved from https://repositorio.unesp.br/bitstream/ handle/11449/103060/carvalho_rj_dr_guara. pdf? sequence $=1$ \&isAllowed $=y$.

[3] Congreso de la República (20 de agosto del 2011). Ley 29783. Ley de Seguridad y Salud en el Trabajo. Diario Oficial El Peruano, Normas Legales 448694-448706.

[4] Cooper, M. D. (2000). Towards a model of safety culture. Safety Science, 36, 111-136. Retrieved from http://www.behavioral-safety.com/articles/ Towards_a_model_of_safety_culture.pdf.

[5] Gadd, S. (2002). Safety Culture: a review of the literature. Sheffield, Reino Unido: Health \& Safety Laboratory. Retrieved from http://www. hse.gov.uk/research/hsl_pdf/2002/hsl02-25. pdf.

[6] Grillo, N. (2013). Construcción y validación de una herramienta de gestión para evaluar la cultura de seguridad en entornos industriales. (Doctoral thesis). Universitat Ramon Llull, Barcelona. Retrieved from https://www. tesisenred.net/handle/10803/119823\#page=1.

[7] Guldenmund, F. W. (2000). The nature of Safety Culture: a review of theory and research. Safety Science, 34(1-2), 215-257. Retrieved from https://www.sciencedirect.com/science/ article/pii/S092575350000014X.

[8] Guldenmund, F. W. (2010). Understanding and exploring Safety Culture. Oisterwijk, Netherlands: Uitgeverij Boxpress. Retrieved from https://repository.tudelft.nl/islandora/ object/uuid:30fb9f1c-7daf-41dd-8a5cb6e3acfe0023?collection =research.

[9] Human Engineering for the Health and Safety Executive (2005a). Development and validation of the HMRI safety culture inspection toolkit. Research report 365. Norwich, United Kingdom: HSE Books. Retrieved from http:// www.hse.gov.uk/research/rrpdf/rr365.pdf.

[10] Human Engineering for the Health and Safety Executive (2005b). A review of safety culture and safety climate literature for the development of the safety culture inspection toolkit. Research report 367. Norwich, United 
Kingdom: HSE Books. Retrieved from http:// www.hse.gov.uk/research/rrpdf/rr367.pdf.

[11] International Association of Oil \& Gas Producers (2010). A guide to selecting appropriate tools to improve HSE culture. London, United Kingdom: OGP Publications. Retrieved from http://www. learnfromaccidents.com.gridhosted.co.uk/ images/uploads/OGP_435_Selecting_the right_tool.pdf.

[12] International Nuclear Safety Advisory Group (1991). Safety Culture. A report by International Nuclear Safety Advisory Group. Safety Series 75-INSAG-4. Vienna, Austria: IAEA. Retrieved from https://www-pub.iaea.org/MTCD/ publications/PDF/Pub882_web.pdf.

[13] International Nuclear Safety Advisory Group (1992). The Chernobyl Accident-Updating of INSAG-1. Safety Series 75-INSAG-7. Vienna, Austria: IAEA. Retrieved from https://www-pub. iaea.org/MTCD/publications/PDF/Pub913e_ web.pdf.

[14] International Nuclear Safety Advisory Group (2002). Key practical issues in strengthening Safety Culture. Safety Series INSAG-15. Vienna, Austria: IAEA. Retrieved from https:// www-pub.iaea.org/MTCD/Publications/PDF/ Pub1137_scr.pdf.
[15] Ministerio de Trabajo y Promoción de Empleo (25 de abril del 2012). Reglamento de la Ley de Seguridad y Salud en el Trabajo, Decreto Supremo N. ${ }^{\circ}$ 005-2012-TR. Diario Oficial El Peruano, Normas Legales 464861-454880.

[16] Morales-Vallejo P. (2011). Guía para construir cuestionarios y escalas de actitudes. Guatemala: Universidad Rafael Landívar. Retrieved from http://www.upcomillas. es/personal/peter/otrosdocumentos/ Guiaparaconstruirescalasdeactitudes.pdf.

[17] The Keil Centre for the Health and Safety Executive (2000). Safety culture maturity model. Offshore technology report 2000/049. Norwich, United Kingdom: HSE Books. Retrieved from http://www.hse.gov.uk/research/otopdf/2000/ oto00049.pdf.

[18] The Rt Hon Lord Cullen PC (2001). The Ladbroke Grove Rail Inquiry. Part 2 report. Norwich, United Kingdom: HSE Books. Retrieved from https://orr.gov.uk/_data/assets/ pdf_file/0020/5663/incident-ladbrokegroveIgri2.pdf. 